\title{
Translation of Classics by JX Native Literati of Song Dynasty under Foregrounding Theory*
}

\author{
Yuying Li \\ Foreign Languages College, Jiangxi Normal University, Nanchang, China \\ Yaping Gao \\ Foreign Languages College, Jiangxi Normal University, Nanchang, China
}

\begin{abstract}
As a symbolic feature of the language forms of literature, foregrounding is closely connected with the theme and aesthetic value of literary works. Through an analysis of some classics by Jiangxi native literati in Song Dynasty, the thesis focuses on the significance of foregrounding theory to literary translation or even to general translation. With a case study of the classics from four aspects of foregrounding theory, namely, phonological deviation, lexical deviation, semantic deviation and graphological deviation, the research would illustrate foregrounding language in literature and its applicability to classics translation in detail.
\end{abstract}

Index Terms - foregrounding theory, classics translation, JX native literati

\section{INTRODUCTION}

Since its advent, the foregrounding theory has undergone a long period of development. In Chinese history, Jiangxi has been a home of literati and produced a great number of literary works that are still being appreciated and treasured today. As most of the classics in Song Dynasty are shi and $c i$, the thesis would focus on making analysis of them. It intends to discuss the significance of foregrounding theory to literary translation or even general translation from 4 aspects of foregrounding phenomena by studying some classics of Jiangxi native literati in Song Dynasty. On this foundation, the essay first introduces the definition of foregrounding by scholars at home and abroad, then analyzes the function of foregrounding language and the relationship between foregrounding language and texts by concrete cases. In the end, it draws a conclusion on translation strategies of the foregrounding language in classics translation.

\section{FOREGROUNDING THEORY AND CLASSICS TRANSLATION}

\section{A. Foregrounding Theory}

Foregrounding is an important concept of literary language applied to define stylistic process, which is also referred to as stylistic variation or prominence. Foregrounding is not merely a term in literary stylistics, and it also has a presence in pragmatics and discourse analysis. Foregrounding language is often deviated from linguistic norms and prominent language features. It can be traced back to the Czech theorist Jan Mukarovsky who believed that it was related to automatization, that is, the deautomatization of some communicative behavior. Automatization makes communicative activity regular, while foregrounding means violating this rule (Mukarovsky, 1964). Together with other linguists of the Prague school such as Jakobson, he developed the concept of language foregrounding and prominence. Jakobson also put forward the concept of literariness that refers to the abnormal use of language (deviation). The information needed to understand new ones for hearers is background information, and the more important fresh information is called foregrounded information. Foregrounding is a type of intentional deviation from arts and it can be divided into quantitative foregrounding and qualitative foregrounding. Based on the two categories, Leech (2001) divided qualitative foregrounding into eight branches including lexical deviation, phonological deviation, grammatical deviation, graphological deviation, semantic deviation, dialectal deviation, deviation of register and deviation of historical period. Halliday believed that foregrounding was a kind of "motivated prominence". And Levin classified deviation into quantitative deviation and qualitative deviation, which was consistent with Leech and Short's classification.

\section{B. Foregrounding Theory and Classics Translation in Song Dynasty}

The research on foregrounding is mainly within one language both at home and abroad. Most of scholars place their focus on how to apply foregrounding theory to literary criticism and stylistic analysis, and few have put it into translation practice. Ye Zinan (2000) believes that foregrounding is supposed to be employed in translation, which offers guidance to translation activities and benefits translation criticism. For classics translation, foregrounding theory

\footnotetext{
* Sponsored by On English Translation of Classics by Jiangxi-born Literati in Song Dynasty, a Social Science Planned Research Project of Jiangxi in 2015
} 
is also of great applicability. In general, although the shi of Song Dynasty could not contend with those of Tang Dynasty in terms of quality, it had its own features represented by some famous poets. In the history of literature, Song Dynasty is the golden era of $\mathrm{ci}$. Ci firstly emerged in Tang Dynasty and prevailed in Song Dynasty. The Complete Ci-Poetry of the Song Dynasty included more than 20,000 ci-poems, among which the famous authors are up to 1430 people (Wang, 2009). This is not only because of the special historical background in Song Dynasty, but also the result of the requirements of literature itself for proper methods to spread these classics abroad and stimulate the communication between diverse cultures. Under the foregrounding theory, the case study aims to discuss foregrounding language in shi and $c i$ as well as its significance to translation practice.

\section{CASE ANAlysis Under Foregrounding THEORY}

\section{A. Classics by Jiangxi Native Literati in Song Dynasty}

Song Dynasty was the flourishing period of Jiangxi culture, of which the booming of literature was a prominent symbol. The splendid scenery of Jiangxi literature in Song Dynasty constituted a magnificent landscape of the literary circle in this phase. JX native literati have achieved fruitful outcomes in literary creation and made outstanding contributions in Song Dynasty. But the current study on translation of these excellent classics has been paid less attention. As an important part of literary translation, the translation of shi and $c i$ by literati of JX origin in Song Dynasty is still in the state of wasteland or half-wasteland and thus remains an area of significant research value.

\section{B. Case Analysis under Foregrounding Theory}

According to the classification of foregrounding by Leech, the essay would discuss the translation of some classics by Jiangxi native literati of Song Dynasty from the following four aspects. Meanwhile, the analysis would take background information and cultural factors into full consideration so as to conduct a more comprehensive and reasonable case study.

1. Phonological Deviation

Phonological deviation means the specialization of pronunciation, involving stress, rhythm and intonation. Both in Chinese and English, phonology is an indispensable element for literary language, especially the poetic language. In poetry, phonological deviations that occur frequently include alliteration, end rhymes, assonance, consonance etc.

\section{Example 1:}

\section{The original:}

文天祥. 《过零丁洋》(Wang, 1995, p.120)

辛苦遭逢起一经, 干戈寥落四周星。

山河破碎风飘絮, 身世浮沉雨打萍。

惶恐滩头说惶恐, 零丁洋里叹零丁。

人生自古谁无死? 留取丹心照汗青。

\section{The translation:}

Crossing the Lonely Ocean (Wang, 1995, p.120)

Through painstaking mastery

Of the classics, 1 have risen high;

But four years of raging war have well-nigh

Brought all-round destitution and ruin

My shattered country does remind

Me of willow-catkins swept by wind;

My life's vicissitudes attain

The aspect of duck-weeds beaten by rain.

At th'Frightful Shallows we fought our way.

They'd tell the frightful battle never won,

And on the Lonely Ocean I could but sigh

For being captured, and all alone.

Down through the ages, whoever that lived

Has not in death ended his life?

I wish to leave but a loyal heart

Shining red in History's archive.

Analysis: Wen Tianxiang is a national hero and writer in the late Southern Song Dynasty. As a celebrated Jiangxi native poet, Wen's story of fighting against the alien invasion having been told by the Chinese people over the past hundreds of years, with his loyalty and passionate patriotism inspired countless people to safeguard the interests of Chinese nation. Chiang Kai-shek once remarked that the loyalty and great personality of Wen was not only the glory of Jiangxi, but the eternal pride of the whole nation (Cai, 2015). Affected by itinerant poets, Wen's poetic style was relatively mediocre in his early life, which became very impressive for its high spirit of patriotism later. Although Wen's poems are not large in number, most of them are brimming with awe-aspiring power and embody the heroic spirits of 
the poet.

This poem is composed by Wen after being captured so as to reflect his ambition and patriotic sentiments. The first line “辛苦遭逢起一经, 干戈胗落四周星。” is a brief review of his life, and the two in the middle describe a country destined to collapse in a precarious situation. In this case, he does not get worried about his own fate, but expresses a deep sense of sadness and self-denunciation for the sufferings his country went through. The last sentence is a highlight of the poem, which conveys Wen's love and sacrifice for his country. It is an intensive manifestation of Chinese traditional virtues. In the original poem, the foregrounding language is featured as phonological and rhythmic. “干戈”, “寥落”, “身世”, “滩头” are alliterative words, and “零丁”\&“惶恐” are assonance words occurred twice. The combination of these words exactly reflects the vicissitudes Wen has suffered from and the fluctuation of his mind. Confronted with alien invasion, the poet set about to be an official and then participated in the war to resist the intrusion. Unfortunately, he failed in the war and his country was broken. The consecutive occurrence of “干戈” and “胗落” is a portrayal of Wen's sorrowful and gloomy mood. After being captured, Wen felt extremely guilty and lonely, and "零 丁”\&“惶恐” multiplied such feelings to a new stage. Finally, the poet's thought was turned into the sublime in the line “人生自古谁无死? 留取丹心照汗青”, pushing the poem to the climax. While in the translation, the alliterative words and assonance words are retained to the utmost. For example, the "four" \&"war" and "Me" \&"willow-catkins" \&"wind". Although they are not fully equivalent to the original one, the meaning and emotions are basically expressed. "The four years of war" emphasizes that it is a long-term war with cruelty, and the "Me of willow-catkins swept by wind" implies Wen's desperate fate, both of them are intensive embodiment of sadness and tragedy. Besides, there are additional end rhymes in the translation. Both the "remind"\&"wind" and "attain"\&"rain" enhance the metre and tone of the poem, which is also a creation and artifice for the target text. As for the assonance words “零丁" $\&$ “惶恐”, the repetition in alternatives "frightful Shallows" \&"frightful battle" and "Lonely Ocean" $\&$ "alone" also focus on the poet's fear and loneliness in this situation. From the perspective of phonological deviation in foregrounding, the target poem has represented the feature as much as possible, which in return interprets the deep emotions in the heart of the poet.

2. Semantic Deviation

Semantic deviation refers to the abnormal, absurd or ambiguous meaning of a sentence or component. Semantic deviation can sometimes deepen the connotation of texts and create more complex emotions, of which the following example is a manifestation.

Example 2:

The original:

晏殊. 《浣溪沙》(Xu, 2007, p.305)

一曲新词酒一杯, 去年天气旧亭台。夕阳西下几时回?

无可奈何花落去, 似曾相识燕归来。小园径独徘徊。

The translation:

\section{Version 1:}

Silk-Washing Stream (Xu, 2007, p.305)

Yan Shu

A song filled with new words, a cup filled with old wine,

The bower is last year's, the weather is as fine.

Will last year reappear as the sun on decline?

Deeply I sigh for the fallen flowers in vain;

Vaguely I seem to know the swallows come again.

In fragrant garden path alone I still remain.

Version 2:

Bleaching Silk in the Stream (Zhuo, 2008, P.20)

Yan Shu

For each newly-writ song I drink a cup of wine,

In the same pavilion and weather as last year.

Would you'er return? Alas, the sun's on th'decline!

In spite of my wish the flowers fall there and here;

Th'swallows, old friends as it were, are back. I alone

Pace on the garden's flower-fring'd path without cheer.

Analysis: Yan Shu is a ci-poet having far-reaching influence in Northern Song Dynasty. Along with Ouyang Xiu, Yan Shu is acknowledged as the pioneer of the traditional genre of $c i$ in Song Dynasty. Yan Shu is a custodian of the $c i$-poetic style in Southern Tang Dynasty, and the "Jiangxi Ci-poetry School" represented by him has laid a solid foundation for the revitalization of $c i$ in Song Dynasty. His work Zhuyuci is deemed as one of the highest achievements in $c i$ in the early Northern Song Dynasty. However, the 130 ci-poems in Zhuyuci are not full of "zhu" and "yu", but "wine" and "worry" (Qian, 2012). In Zhuyuci, the "wine" mainly refers to "relieving sadness by drinking", with only a few meaning "drinking for entertainment and banquet". The "worry" involves anxiety to the shortness of life and to the complexity of human beings. In general, the $c i$-poetic style of Yan Shu is graceful and sentimental. Hundreds of years 
later, another intellectual Wang Guowei (2010) regards his $c i$ as worries about life from the perspective of philosophy, which indicates that Zhuyuci is a ci collection worth of appreciating for future generations.

The $c i$-poem Huanxisha mainly memorized the fleeting hours by describing the scene of spring and thus reflected a sentimental love for the past time. It seemed to depict the common phenomenon in life, however, there was an underlying philosophy that inspired people to think about life or even the universe from a high level. The $c i$-poem included profound themes such as the eternity of time and the limitation of life in a very subtle and indirect manner. In lines“一曲新词酒一杯, 去年天气旧亭台。夕阳西下几时回?”, the meaning was ambiguous for its complex emotions the author wants to convey, which is an embodiment of semantic deviation in foregrounding. By making a description of the view in front of the author, it integrated the sense of nostalgia, grief and many other delicate feelings, of which both the two translators have different understanding. Especially for the one “夕阳西下几时回?”, it was not a simple question that meant "When will the sunrise come back", but an absurdity that cannot be comprehended literally. What the author wanted to convey was that "will the past time return" to memorize the days. In regard to this, the first version "Will last year reappear as the sun on decline?" is more proper than the second one "Would you'er return? Alas, the sun's on th'decline!". It is the ambiguity and absurdity of the meaning that brings about two kinds of distinct renderings. Both of them adopt the amplification method to make the meaning more clear. However, the first version is better in delivering the thoughts of the original text-the aspiration to return to the past and the appeal to cherish time, while the second version simplifies the emotions in the poem and narrows the space of imagination for readers. According to this, translators are supposed to understand both the surface and deep meaning of texts for the sake of making the translation more exact.

3. Grammatical Deviation

Grammatical deviation relates to language uses that do not conform to grammatical rules of the language (Qin, 1983). Compared with English, the grammatical rules of Chinese are more flexible and context-oriented. In literature language, grammatical deviation is also an effective medium to achieve certain highlight.

\section{Example 3:}

The original:

王安石·《桂枝香·金陵怀古》(Zhuo, 2008, P.31)

念往昔、繁华竞逐, 叹门外楼头, 悲恨相续。千古凭高对此, 漫嗟荣辱。

六朝旧事随流水, 但寒烟芳草凝绿。至今商女, 时时犹唱, 后庭遗曲。

\section{The translation:}

Fragrance of Laurel Branch (Zhuo, 2008, P.32)

The days gone by

Saw people in opulence vie.

Alas! Shame on shame came under the walls,

In palace halls.

Leaning on rails, in vain I utter sighs

Over ancient kingdomse fall and rise.

The running water saw the Six Dynasties pass,

But I see only chilly mist and withered grass.

Even now and again

The songstresses still sing

The song composed in vain

By a captive king.

Analysis: Different from Yan Shu, Wang Anshi is the initial JX native poet to make innovation in $c i$ so as to break the traditional style in Northern Song Dynasty (Zhang, 1986). Although the existed ci-poems by Wang Anshi are relatively few, they completely shake off the style of Hua-jan ci prevailing in the late Tang and Five Dynasties. More importantly, Wang Anshi does not limited to the traditional subjects of ci taking love and entertainment as the core and incorporates themes as many as possible into his writing. For $c i$, most of the poets hold the view that " $c i$ ought to focus on love and romance, not the history and reality." Most nostalgic ci began to appear until the middle of Northern Song Dynasty. And it was the ci-poem Guizhixiang by Wang Anshi that first won reputation and status for nostalgic $c i$. Guizhixiang is a slow-rhymed $c i$-poem that represents Wang's political indignation to the society by quoting stories and allusions in Six Dynasties. Its first half described the natural scene; and the next part sighed on the present situation by recollecting the past times, which embodied a deep feeling of nostalgia and worry. Briefly speaking, Wang Anshi had completely get rid of the traditional $c i$-poetic style and made a great success on the road of "writing $c i$ based on shi".

In a shining Autumn day after raining, the author climbed up to one of the highest buildings in Nanjing City with his friends. Facing the magnificent landscape of Jinling, he began to recall the history of Six Dynasties and therefore wrote this $c i$-poem. By making judgement on the rise and fall of the past dynasties, it showed a deep feeling of lament to political reality and revealed the author's mind and bearing as a reformer. Being a witness of history, the natural scenery of Jinling still reminded people of the lessons from the past. But what about the reality? The author chose to state it with an allusion, namely, the last line “至今商女, 时时犹唱, 后庭遗曲。” originated from the poem of Du Mu “商女不知 
亡国恨，隔江犹唱《后庭花》”. For Du Mu, the song stresses only sang without understanding the content of the song, let alone the sense of regret and sadness on subjugation it contained. However, apart from them, how many people were there who still remember the history? It showed the poet's painful indignation to the decline of Tang Dynasty. For Wang Anshi, he was also indignant to Northern Song Dynasty by borrowing from Du Mu's poem. Meanwhile, the tone of “至 今商女, 时时犹唱, 后庭遗曲。” is intensified by adding two commas. Actually, the sentence would be grammatically complete and adequate without the commas. By cutting the line into three phrases of four characters, the comma functions as a pause that can prolong the sentence, strengthening its rhythm and emotion, hence putting an emphasis on the $c i$-poet's reflection to the history and present time. While in the translation, the commas were omitted and the line was replaced by a simple sentence. In English, although the structure inside a sentence is flexible and changeable, it is unusual to add or omit a punctuation randomly as the meaning may be disrupted. Besides, although the four-character phrases are often rhythmic and coherent in Chinese, they are mostly loose and awkward in English. Thus, the translation "Even now and again the songstresses still sing the song composed in vain by a captive king" is quite natural and authentic, though it has not retained the foregrounding language of the original one.

4. Lexical Deviation

Lexical deviation mainly refers to the creation of new words and new meaning (Wang, 2013). Words are the foundation of content, and the choice of words is an important standard to measure the quality of a literary work. Lexical deviation has the function of injecting vitality to texts, and it is quite common in literary language.

\section{Example 4:}

The original:

姜篔. 《扬州慢》(Xu, 2007, P.178)

淮左名都, 竹西佳处, 解鞍少驻初程。过春风十里, 尽荠麦青青。自胡马窥江去后, 废池乔木, 犹厌言兵。 渐黄昏、清角吹寒, 都在空城。

杜郎俊赏, 算而今重到须惊。纵豆冦词工, 青楼梦好, 难赋深情。二十四桥仍在, 波心荡冷月无声。 念桥边红药, 年年知为谁生。

\section{The translation: \\ Xu's Version:}

To the Tune of Yang Zhou Man (Xu, 2007, P.178)

As I walk along the road

Once bathed in a reach of vernal breezes

I see green field cress on all sides.

Since Tartar cavalry pressed upon the Yangtze,

The city with abandoned moat and towering trees

Still hates all mention of the war.

As evening sets in, in the empty city

Chilly horns are echoing.

If $\mathrm{Du} \mathrm{Mu}$ the connoisseur of bygone beauty

Returned to life, he'd lament the lost glory.

His magic pen that described a cardamom-like girl

And dream-like time in blue mansions

Can no more tell a romantic story.

\section{Zhuo's Version:}

Song of Yangzhou with a Slow Rhythm (Zhuo, 2008, P.148)

What us'd to be a ten-li thriving way

Is now overgrown with all kinds of weeds.

Since to th'river come th' covetous foe's steeds,

E'en th'trees and desolate ponds may dread

Th'mention of th'flames of war, which had o'erspread

Th'land. In th'looted city, when dusk draws near,

Signal horns sound plaintive and drear.

$\mathrm{Du} \mathrm{Mu}$, who extols the place in his verse,

Would be stunn'd if he were reviv'd, I deem;

And I'd defy his gifts to tell the grief o'er th's curse,

Though nice are his poems on reality and dream.

Analysis: Jiang Kui, a famous writer and musician in Southern Song Dynasty, is also a representative of "Jiangxi $C i$-poetry School". He is very proficient in music and fond of showing his inner world by composing $c i$. The $c i$ by Jiang Kui are characterized by musical and rhythmic beauty, with moving images created by various artistic means (Yan\&Luo, 2015). He is renowned for the fluid and mild writing style, as well as the images adopting from the former shi and $c i$. The $c i$-poem Yangzhouman is an example that fully represents Jiang Kui's personal style. It adsorbs some of the poems and images created by $\mathrm{Du} \mathrm{Mu}$ of Tang Dynasty, and there are quantities of innovations on the level of word. The 
$c i$-poem depicted a picture of desolation with graceful and brief language. It not only complained the rulers of Jin Dynasty about the disasters caused by their aggression, but also denounced the policy of concession taken by the rulers of Southern Song Dynasty.

The selected $c i$-poem is an intensive embodiment of the $c i$-poet's elegant and dynamic language. It mainly lies in words such as “清” “寒”“空”“波心”“冷月”, which further amplify the linguistic features of the whole text. By making a contrast of the present and past scenes of Yangzhou, the author revealed a great pity for the destruction of a regime and emphasized the vicissitudes in life. The $c i$-poem contains a bound of lexical deviations, involving “过春风十里”, “清角吹寒”, “豆莞词工” etc. All these expressions not only reflect the profound knowledge of the author, but also produce more vitality and vigor. For“过春风十里”, the“十里” dose not really refer to “ten-li”, it is merely a rough description of the breeze by concrete unit of measure to emphasize that the wind is in a large scale. Therefore, Xu's translation" a reach of vernal breezes" is more appropriate than " a ten-li thriving way". "a reach of " is often applied to modify grass or woodland that means a certain range, here it is employed to describe "breeze", which roughly equals to "here and there". It is also a type of lexical deviation that are more equivalent to the meaning of "十里" in the original $c i$-poem. Then for “清角吹寒”, the “寒” is not “coldness” but "plaintive melody" that can bring people sense of coldness and sorrow. In Xu's version, the word "chilly" is applied to modify "horns", which is also endowed with sadness rather than coldness. By contrast, Zhuo's version "Signal horns sound plaintive and drear." is quite normal and does not embody similar connotation. In Chinese, the word “豆莞” usually refers to the age of 13 14 of young ladies. Here the author adopts“豆冦” to describe a poet's writing of charms and colors. Concerning this one, Xu renders it as "His magic pen", which transfers the meaning of the original one creatively. The one who owns a magic pen is sure to own the ability to write well. While Zhuo's rendering "nice are his poems on reality and dream." is more like a paraphrase of the original poem, thus is comparatively less attractive. Based on the above foregrounding language, Xu's translation is more acceptable and creative, and it is also worthy of learning by translators on how to make dynamic equivalence between two languages.

\section{CONCLUSION}

Translation is an activity with its own regularity that needs to be further explored so as to establish an evaluation system in a more overall manner. Introducing foregrounding theory into classics translation can provide a new perspective for translators to represent the literary language of works. At the same time, it benefits to set reasonable principles for translation criticism. Foregrounding language is closely related to the literariness and aesthetic values of literary works including the translation of shi and $\mathrm{ci}$. In order to represent foregrounding language better, translators are required to go deep into the analysis of language deviation and conclude more concrete translation strategies. It is unquestionable that the relations between foregrounding theory and translation are complicated and thus require to be researched in detail. In this sense, translators ought to be more sensitive to foregrounding language and manage to represent it as much as possible. In addition, the significance of foregrounding theory to classics or even literary translation needs to be further discussed both theoretically and practically.

\section{REFERENCES}

[1] Cai, D. F. (2015). The Popular Romance of Chinese Dynasties. Beijing: Xinhua Press.

[2] Leech. G N. (2001). A Linguistic Guide to English Poetry. Beijing: Foreign Language Teaching Press.

[3] Mukarovsky, J. (1964). Standard language and poetic language. Washington, DC: Georgetown University Press.

[4] Qian, H. Y.(2012). On the Style of the Ci by Yan Shu. Journal of Peking University (Philosophy and Social Sciences Edition), 2012(01), 60-66.

[5] Qin, X. B. (1983). A Concise Study of English Stylistics. Changsha: Hunan Education Press.

[6] Wang, G. W. (2010). Jen-Chien TZ’u-Hua. Nanjing: Yilin Press.

[7] Wang, R. P. (2009). English Translation of Chinese Classics. Shanghai: Shanghai Foreign Language Education Press.

[8] Wang, S. Y. (2013). A Synopsis of English Stylistics. Jinan: Shandong University Press.

[9] Wang, Z. H. (1995). Selected Lyrics on Themes of Patriotism and Moral Integrity. Beijing: China Translation Corporation.

[10] Xu, Y. C. (2007). 300 Song Lyrics. Beijing: China Translation and Publishing Corporation.

[11] Yan, H. \& Luo, Q. Q. (2015). The Special Aesthetics of Jiang Kui’s Song Lyrics. Jiangxi Social Sciences, 2015(06), 90-94.

[12] Ye, Z. N. (2000). Advanced English-Chinese Translation Theory and Practice. Beijing: Tsinghua University Press.

[13] Zhang, Z. L. (1986). On the Style of Guizhixiang-Jinlinghuaigu by Wang Anshi. Press Circles, 1986(04), 42-43.

[14] Zhuo, Z. Y. (2008). A Collection of Ci-poetry. Shanghai: Shanghai Foreign Language Education Press.

Yuying Li was born in Jiangxi Province, China in 1964. She is currently a professor in Translation Theory and Practice, Jiangxi Normal University, Nanchang, China. She has published papers in both Chinese and international academic journals.

Yaping Gao was born in Jiangxi Province, China in 1994. She is currently a postgraduate in Translation Theory and Practice, Jiangxi Normal University, Nanchang, China. 